\title{
COMPARISON OF LEARNING AND MEMORY OF EASTERN (APIS CERANA CERANA) AND WESTERN HONEY BEES (APIS MELLIFERA L.)
}

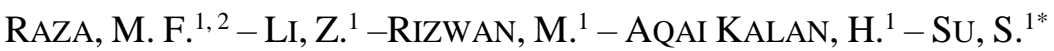 \\ ${ }^{1}$ College of Bee Science, Fujian Agriculture and Forestry University \\ Fuzhou, 35002, China \\ ${ }^{2}$ College of Life Sciences, Fujian Agriculture and Forestry University \\ Fuzhou, 35002, China \\ *Corresponding author \\ e-mail: susongkun@zju.edu.cn; phone: +86-1366-500-5782 \\ (Received $20^{\text {th }}$ Nov 2018; accepted $14^{\text {th }}$ Feb 2019)
}

\begin{abstract}
Honeybees are valuable pollinators strongly influencing ecosystem conservation, stability, genetic variation and ecological relationships in the floral diversity, plant community, evolution, and specialization. Honeybee is an excellent model organism for research on learning and memory among invertebrates. In their behavior, the subjective evaluation of a sucrose stimulus influences the behavioral performance. Here we report comparative behavioral data on the sensitization, habituation, short-term and long-term memory of Apis cerana and A. mellifera in China, using different sucrose concentrations. $A$. mellifera foragers have higher sucrose responsiveness than A. cerana foragers when tested using a proboscis extension response (PER) assay. Sensitization and habituation are well-known forms of nonassociative learning. A. cerana took less number of habituation trials as compared to A. mellifera. Thus, these results significantly showed that $A$. cerana took less time to dishabituate. The sensitive stimuli of $A$. cerana against lemon extract were more than A. mellifera. In addition, although A. mellifera showed more sensitive stimuli against apple extract than A. cerana cerana, A. mellifera displayed significantly more learning and memory behavior than A. cerana after 2 and 24 hours.
\end{abstract}

Keywords: olfactory learning, honeybee, proboscis extension response, odors, sensitization

\section{Introduction}

In ecosystem functioning, diversity is a major and important component (Tilman et al., 2001; Duffy et al., 2007). Honey bees are key contributors and the best pollinator species in the world in natural ecosystems and functions (Ebeling et al., 2011). Species richness can stabilize and play an important role in ecosystem services, including pollination to environmental disturbance and variability pollination. Honeybees are crucial to ecosystems and environment, wild plant growth, wildlife habitats, and biodiversity as a pollinator and food source. The eastern honeybee (Apis cerana) is a species of honeybee found in southeastern and southern Asia, including China, Pakistan, Korea, Malaysia, Japan, Bangladesh, Nepal, Papua New Guinea, Australia Solomon Islands and India (Engel, 1999; Oldroyd and Wongsiri, 2009). The western honeybee or European honeybee (Apis mellifera) is the most common of the 7-12 species of honeybee worldwide. The genus name Apis is Latin for "bee", and mellifera is the Latin for "honey-bearing", referring to the species' production of honey. As the wasps come close to the honeybee nest (Apis cerana cerana), extra guard bees are alerted, which in turn increases their chance of being killed by heat-balling bees. Heat balling is a distinctive defense system in which several hundred bees surround the wasp in a tight ball and vibrate their muscles in an effort to produce heat and effectively kill the wasp inside. Apis mellifera colonies can reach sizes of up to 50,000 or more individuals, Apis cerana colonies are relatively small, with only around 
6,000 to 7,000 workers. Apis cerana is found predominantly in the Eastern Asian region of the world, while Apis mellifera is found predominantly in the Western European and African region of the world (Winston, 1991). A. cerana recruits threefold more guard bees to stave off predation than A. mellifera. Honeybees avoiding wasps' predation behavior, A. cerana can efficaciously escape from wasp's predation through changing flying behavior, but Apis mellifera cannot. Apis cerana has been recognized as a lower pathogen occurrence species versus Apis mellifera. Hygienic response (removing freeze killed brood and opening cell caps) of Apis cerana is faster and better than Apis mellifera (Lin et al., 2016). A. cerana visited more flowers and took greater time for completing a single foraging trip on apple bloom than A. mellifera (Ahmad et al., 2017). The honeybees must have to learn and memorize the color of flower, how to navigate, and what plants are rich food source. Learning and memory are basic and essential capabilities for dance communication and foraging behavior. Flowers shape, odor, and color are learned during foraging (Sandoz et al., 2002; Hooper et al., 2005; Haddad et al., 2011).

Most animal species are capable of discriminating between varieties of odors. This ability is usually crucial for the organization such as feeding, mating, and social communication, as well as for the processes of learning and memory that are associated with these behaviors (Leonard et al., 2011). Insects constitute successful models for the study of learning and memory due to their remarkable learning abilities (Menzel, 1999; Mizunami et al., 2004; Davis, 2005; Giurfa, 2007). Among insects, honey bees (Apis mellifera) are reported to have the highest and broadest range of learning abilities (Menzel, 1999; Giurfa et al., 2001; Giurfa, 2007; Sandoz, 2011; Giurfa and Sandoz, 2012). Honey bees are able to associate a food reward with different sensory stimuli such as odors, colors and visual patterns, tactile or thermal stimuli (Menzel, 1999; Giurfa, 2007). Both A. mellifera and A. cerana are kept in China, with about four million colonies and three million colonies, respectively (Hongliang, 2007). A. cerana colonies are mainly kept in mountainous locations, while A. mellifera colonies are usually transported across the country to follow the blooming of flowers (WANG et al., 2007). Honey bees (A. mellifera) are well known for their communication and orientation skills and for their impressive learning capability (Menzel and Giurfa, 2001; Menzel et al., 2006). Because the survival of a honeybee colony depends on the exploitation of food sources, forager bees learn and memorize variable flower sites as well as their profitability. Forager bees can be easily trained in natural settings where they forage at a feeding site and learn the related signals such as odor or color. Appetitive associative learning can also be studied under controlled conditions in the laboratory by conditioning the proboscis extension response (PER) of individually harnessed honey bees (Bitterman et al., 1983; Kesner and Olton, 2014).

The proboscis extension reflex is a classical behavioral trait used to determine the learning behavior of honeybees' response to odors. The PER is the behavior of a honey bee that extends her proboscis when a drop of sucrose solution at sufficient concentration is applied to the antennae (Pankiw and Page, 2003). However, studies on learning and memory of honeybees have mostly used harnessed individuals and olfactory learning protocols when the goal was to achieve full control of behavior by the experimenter. The most popular protocol used to this end is the olfactory conditioning of the PER, which is a case of classical conditioning (Takeda, 1961; Vareschi, 1971; Bitterman et al., 1983; Giurfa and Sandoz, 2012). The PER is a reflexive response of hungry bees which is part of their feeding behavior while foraging or within the hive (Frings and Frings, 1949). It occurs when the antennae, tarsi or mouthparts come in contact with sucrose solution; the bee then reflexively extends its proboscis (PER) to 
reach the sucrose solution and drink it. Odors generally do not evoke the PER in bees naïve to the experimental conditions. During conditioning, an odor (CS) is presented in close temporal association with sucrose solution (US). At the end of training, the odor alone elicits the PER, indicating that the bee has learned the odor-sucrose association (Takeda, 1961; Bitterman et al., 1983). PER is usually recorded as a dichotomous response ( 1 or 0$)$, which can thus be used as an index for learning and memory performances. The protocol of olfactory PER conditioning, first established by (Takeda, 1961) and was later standardized by (Bitterman et al., 1983).

Habituation and sensitization are two well-known forms of non-associative learning, which change the response probability of an animal towards a stimulus following repeated exposure to the same stimulus (habituation) or exposure to a strong yet different stimulus (sensitization). Habituation is a response decrement to a monotonously repeated stimulus (Braun and Bicker, 1992). While sensitization implies that a strong or particularly salient stimulus enhances the response of the bee to a test stimulus (Menzel, 1999). A honeybee extends its proboscis when its antennae are stimulated with a sucrose solution whose concentration exceeds its sucrose response threshold. When low-concentrated sucrose solutions are repeatedly applied to the antennae of a bee with a short interval between two stimulations ("inter-trial interval"), the proboscis extension response habituates (Braun and Bicker, 1992; Menzel., 1993; Scheiner et al., 2004). The bee no longer shows proboscis extension when its antennae are stimulated with this sucrose stimulus. Similar to habituation, the degree of sensitization depends on the gustatory responsiveness of the bee and the strength (i.e. the sucrose concentration) of the sensitizing stimulus (Menzel el al., 1993; Scheiner el al., 2004).

Sensitization can be easily tested in honeybees using an odorant and a sucrose stimulus. Most bees do not show spontaneous proboscis extension when their antennae are stimulated with an odorant such as carnation, citral or geraniol. When their antennae are briefly stimulated with a high-concentrated sucrose solution $30 \%$ or $50 \%$ for example) and with an odorant immediately afterward, the bees become sensitized to the odorant (Menzel et al., 1993; Hammer et al., 1994). Honey bees display proboscis extension in response to antennal stimulation with the odorant, which previously did not evoke a visible response. Note that sensitization to an odor is different from classical olfactory conditioning because: (1) it does not require repeated pairings of odor and sucrose solution, as well as (2) it only occurs up to two minutes after olfactory stimulation. For a century now, honeybee (A. mellifera) has been a key insect model in which behavioral, neuroanatomical, and neurophysiological approaches have been performed to unravel the basis of olfaction and olfactory learning. Honey bees are social insects which present a wide range of behaviors relying on olfaction both within and outside of the colony (Seeley, 1995).

The honey bee is well-known for its excellent associative learning capacities in a wide range of assays (Menzel and Müller, 1996; Menzel and Giurfa, 2001; Giurfa, 2007; Matsumoto et al., 2012). Both in the field and under the controlled conditions of a laboratory, bees reliably learn and remember odors, shapes and surface structures. Learning of colors is much more complicated under laboratory conditions (Gerber and Ullrich, 1999; Mota et al., 2011). Bees can be trained in classical and operant conditioning paradigms. In classical conditioning, honey bee learns to associate an originally neutral stimulus (conditioned stimulus, CS) with a biologically relevant stimulus (unconditioned stimulus, US), while in operant conditioning, a bee evaluates its own behavior and its consequences (Menzel, 2012). 
Any study of memory must carefully separate the effect of storage and recall mechanisms (Spear et al., 1990). The results reported here indicate a complex relationship between olfactory storage and recall mechanisms in the honeybee. That is, what is recalled after memory consolidation (Erber et al., 1980) can be slightly different from the conditioning event, and a lack of a response does not necessarily imply forgetting (Spear et al., 1990). Associative learning is an essential component of the bee's central place foraging behavior and dance communication.

\section{Materials and Methods}

\section{Insect}

Experiments and observations were conducted with colonies of Apis cerana and A. mellifera from March to August 2017. Three colonies of each species (A. cerana and A. mellifera) were set up at an apiary of the College of bee science, Fujian Agriculture and Forestry University, Fuzhou, China. All colonies were queen right and housed in standard Lang troth hives.

\section{Catching bees}

A pyramid (height $24.5 \mathrm{~cm}$, apex $3.5 \mathrm{~cm} \times 3.5 \mathrm{~cm}$, base $18 \mathrm{~cm} \times 18 \mathrm{~cm}$ ) made of UV-translucent Plexiglas was used to catch bees when they departed from the hive and flied toward the sky (Fig. 1A). The Plexiglas was UV-transparent; in order to offer a complete view of celestial cues and thus lure the departing bees into the pyramid, the pyramid was closable at the apex and at the base. For catching bees, the pyramid was held at a frontal distance of about $10-20 \mathrm{~cm}$ from the hive entrance, with the base open and the apex closed. Unexpected movements and standing directly in front of the hive entrance (instead of laterally) were avoided to prevent arousing guard bees. When enough bees were caught, the base was closed and the pyramid was taken to the laboratory. In the laboratory, the pyramid was darkened (except for its apex), for instance by placing a thick cloth over it. Because of their positive photo taxis behavior, bees then tended to leave the pyramid one by one through the apex. Honey bees were individually captured into glass vials. Vials were then placed in crushed ice as long as it is necessary to render the bees motionless (usually between 3 and $5 \mathrm{~min}$ ) so that they were harnessed individually. Cooling time was kept to a minimum as extended cooling impair learning performances (Frost et al., 2011) and survival in the harness.

\section{Harnessing bees}

As soon as the bees ceased their movements, they were being placed in the harnessing tubes. Each bee was fixed within a tube using a piece of adhesive tape placed at the level of the neck, the rest of the body being concealed within the tube. Once fixed in the tube, the bee should only be able to freely move its mouthparts and antennae, thus hiding other body parts from possible contacts with sucrose stimulation. The forelegs of the bees, for instance, should not be able to move freely but should remain enclosed within the tube to avoid interference with olfactory and sucrose stimulation. Each harness tube should be numbered to allow individual identification of the bees throughout the experiment. A rack with numbered boreholes was useful for handling and identifying harnessed bees. 


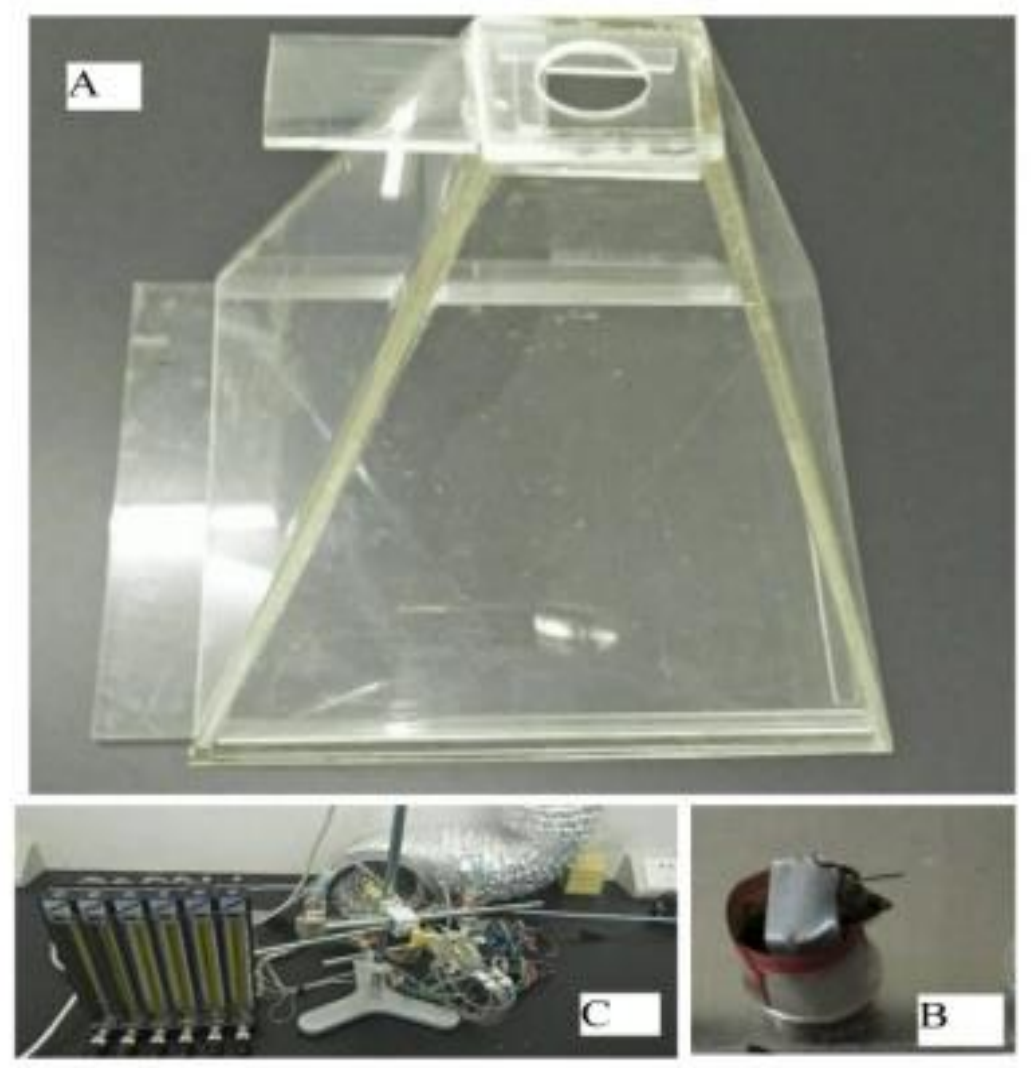

Figure 1. (A) pyramid made of UV-translucent Plexiglas was used to catch bees when they departed from the hive and fly towards the sky, $(\boldsymbol{B})$ each bee was fixed within a tube using a piece of adhesive tape placed at the level of the neck, the rest of the body being concealed within the tube. Once fixed in the tube, the bee should only be able to freely move its mouthparts and antennae, $(\boldsymbol{C})$ the bee is set in front of an odorant Proboscis extension response setup which is controlled by a computer and which sends a constant flow of clean air to the bee

\section{Sucrose concentration}

Explicit control of the bee caste used for conditioning is recommended because foragers are the individuals that exhibit the highest appetitive motivation for sucrose within the hive (Scheiner et al., 2001) and they are, therefore, more appropriate for appetitive olfactory conditioning. Catching and harnessing the bees were conducted as described in section 2.2 and 2.3. Capture of bees departing from the hive in the morning or late afternoon (avoiding mid-day times when young bees performed their first orientation flights) enhanced the probability of obtaining empty foragers for experiments. Empty foragers (i.e. with empty crop) were necessary to ensure highest appetitive motivation for the experiments. After immobilization, the foragers were mounted in the holding tubes like other bees. One hour after mounting, responsiveness to sucrose was tested using the PER. Water and the following six sucrose concentrations were applied to the antennae of each bee: $0.1 \%, 0.3 \%, 1 \%, 3 \%, 10 \%$ and $30 \%(\mathrm{w} / \mathrm{v})$. With each sucrose concentration, it was recorded whether proboscis extension occurred. The inter-trial interval was $2 \mathrm{~min}$. The sum of the responses to water and the six sucrose concentrations represents the gustatory response score (GRS) of an individual and is a measure of its responsiveness to sucrose (Scheiner et al., 2004). Forager's bees were tested sequentially with the series of sugar solution, starting with the lowest concentration. Water was used between each sugar solution to reduce possible sensory 
sensitization to antennal touch (Pankiw et al., 2001). The PER was recorded as ' 1 ' if a bee extended her proboscis after both of her antennae were touched by a toothpick presoaked with a sucrose solution, and ' 0 ' if she did not respond. The responsiveness of 30 bees to each sucrose concentration was expressed as "percent of bees showing PER (\%PER)" by dividing the number of bees that responded to sugar by the total number of tested bees. For example, if 5 bees out of 15 responded to $10 \%$ sugar solution, then the $\%$ PER for this concentration was $5 / 15=33 \%$. The \%PER is a more refined response as compared to PER score because the PER score is a summed response across all the sugar concentrations. Three colonies of each species were measured for this experiment (with $\mathrm{N}=3 \times 2 \times 30=180$ bees tested for both species) (Friedrich, 2004; Yang et al., 2013).

\section{Habituation}

Catching and harnessing the bees were conducted as described in section 2.2 and 2.3. All the bees were fed three drops of $30 \%$ sucrose solution and put in an incubator for one hour. Bees were stimulated five times with $30 \%$ sucrose to induce dishabituation. Habituation of PER was tested by repeated stimulation of an antenna (30\% sucrose Solution) at an inter-stimulus interval of $1 \mathrm{~s}$. The number of PER occurring before five consecutive response failures defines the habituation criterion (Braun and Bicker, 1992; Müller and Hildebrandt, 2002; Scheiner et al., 2004; Pirk et al., 2013).

\section{Sensitization}

Catching and harnessing the bees were conducted as described in section 2.2 and 2.3.use olfactory learning machine for lemon extract for 4 seconds. Two minutes after testing the initial responsiveness to a lemon odor stimulus, the honeybee was sensitized by antennal stimulation with sucrose (30\% sucrose solution). After $20 \mathrm{~s}$, the second odor apple stimulus was presented to test for sensitization (Iqbal and Mueller, 2007).

\section{Learning and memory}

Catching and harnessing the bees were conducted as described in section 2.2 and 2.3. A conditioning trial contained pairing an odor stimulus (apple extract) (conditioned stimulus, CS) with a sucrose reward (30\% sucrose solution) (unconditioned stimulus, US). After the animals received three successive conditioning trials at an inter-trial interval of $2 \mathrm{~min}$, memory tests were performed $2 \mathrm{~h}$ and $24 \mathrm{~h}$ after training.

\section{Statistical analysis}

The significance of the finding for the sucrose responsiveness experiment was tested by two-way ANOVA, two-way ANOVA comparison shows response of Apis mellifera and Apis cerana of different sucrose concentrations (Pérez Claudio et al., 2018; Afik et al., 2006). All observed scores of both groups were compared using a $t$-test or nonparametric equivalents. More than two groups were compared using analysis of variance (ANOVA) or nonparametric equivalents with respective post-hoc tests. Response frequencies were compared using Chi-square tests or multiple-measurement ANOVA (for further details see the BEEBOOK paper on statistical methods (Pirk et al., 2013). The entire data of learning and memory were analyzed through One-Way Analysis of Variance (ANOVA) and the means were compared by Tukey's test ( $\mathrm{P} \leq$ 0.05) with the help of KyPlot ${ }^{\mathrm{TM}}$ v5.0 program (KyensLab Inc., 2017). 


\section{Results}

\section{Sucrose responsiveness in honey bee foragers}

Apis mellifera showed significantly more proboscis extension response than $A$. cerana foragers $(\mathrm{F}=2.879, \mathrm{df}=5$ and $\mathrm{P}<=0.05)$. The mean proboscis extension response of Apis mellifera was significantly higher at $30 \%$ and $10 \%$ of sucrose respectively (Fig. 1). The lowest concentration causing proboscis extension was observed on A. cerana at $0.10 \%$ of sucrose (Fig. 2).

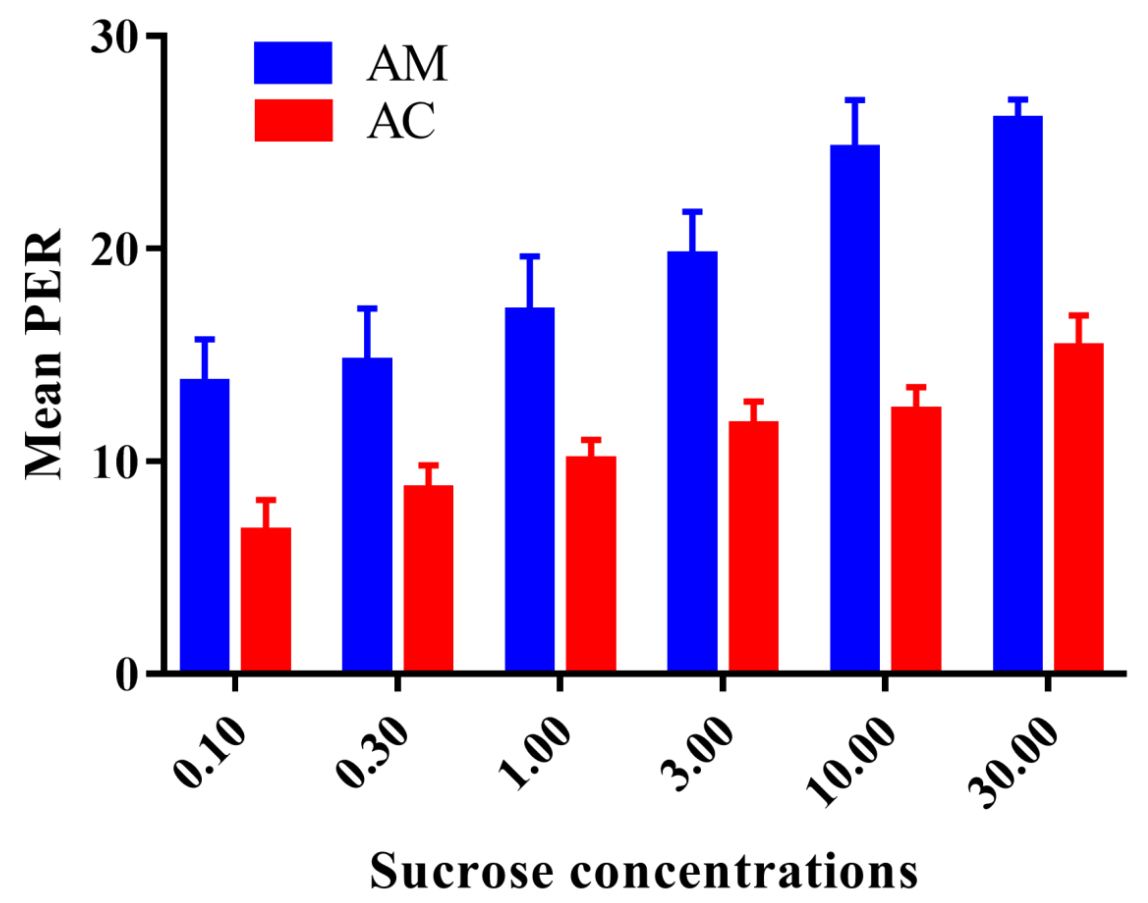

Figure 2. Percentage of bees showing proboscis extension response (mean \pm SE) of foragers of Apis mellifera and A. cerana across different sucrose concentrations. The following data based on three colonies of each species of honeybee. $(N=3 \times 2 \times 20=120$ bees). $N$ (total number of species), 3 (three colonies of each species), 2 (two species Apis cerana cerana, Apis mellifera $L$. were studied) and 20 (number of bees from each colony of both species)

\section{Habituation}

Habituation represents the gradual decrease in responsiveness during a continuous series of repeated stimulations. When the bees were habituated, sucrose stimuli would no longer elicit PER. The habituation rate was assessed by counting the number of trials until no visible movement of the proboscis occurred in five subsequent trials (Braun and Bicker, 1992). A. cerana took less number of habituation trials as compared to $A$. mellifera. Thus, our results indicated that A. cerana took less time to dishabituate (Fig. $3)$. After A (1-20) and B (21-40), habituation trials $77.78 \%$ and $15.56 \%$ bees of $A$. cerana showed proboscis extension response respectively (Fig. 3). 


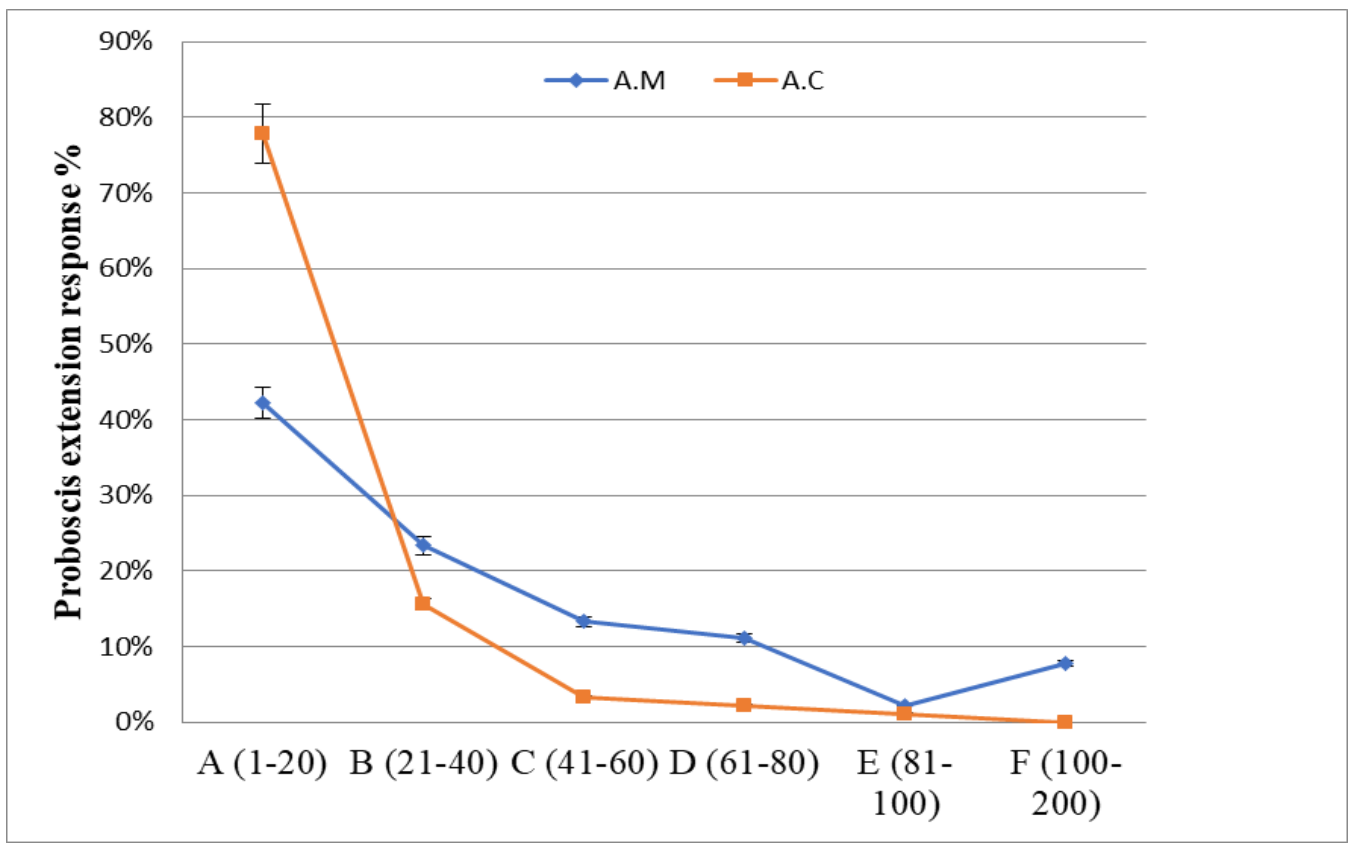

Figure 3. Percentage of Apis cerana and A. mellifera responding to the appetitive stimulation during trials; (A) Habituation of PER $(N=16)$; (B) Dishabituation of PER $(N=10)$

\section{Learning and memory}

Apis mellifera showed significantly stronger learning and memory behavior than $A$. cerana after $2 \mathrm{~h}$ and $24 \mathrm{~h}(\mathrm{df}=3, \mathrm{~F}=18.512821$ and $\mathrm{P}<=0.05)$. The learning and memory behavior of Apis mellifera and Apis cerana after $2 \mathrm{~h}$ and $24 \mathrm{~h}$ was $62.22 \%, 27.28 \%$, $51.11 \%$, and $28 \%$, respectively (Fig. 4).

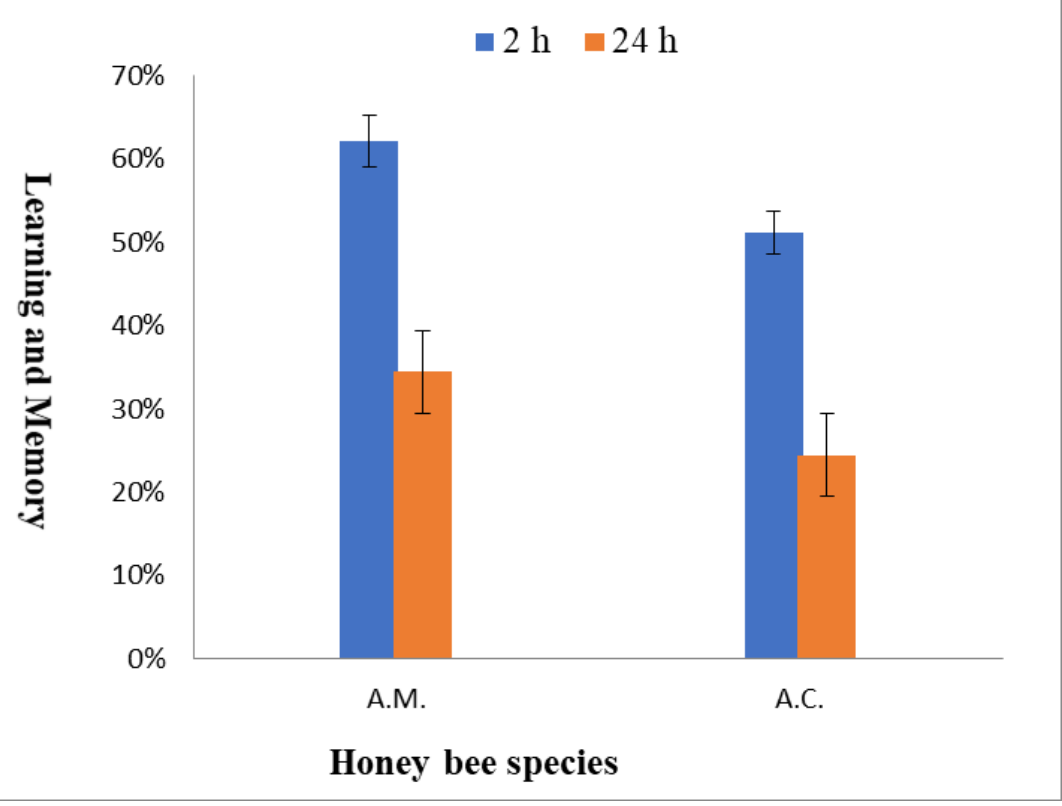

Figure 4. Percentage of learning and memory (mean $\pm S E$ ) of Apis mellifera and A. cerana after $2 \mathrm{~h}$ and $24 \mathrm{~h}$ treatment of $30 \%$ sucrose solution. The following data based on three colonies of each species of honeybee. $(N=3 \times 2 \times 20=120$ bees $)$ 


\section{Sensitization}

The sensitive stimuli of A. cerana against lemon extract were more than A. mellifera $(\mathrm{F}=18.512821, \mathrm{df}=2$ and $\mathrm{P}>0.05 \mathrm{NS})$. The percentage of the sensitivity of $A$. cerana and $A$. mellifera was $29.31 \%$ and $4.44 \%$ against lemon extract, but $A$. mellifera were more sensitive against apple extract than A. cerana. For apple extract, the sensitive responses of $A$. mellifera and A. cerana were $11.63 \%$ and $2.13 \%$ (Fig. 5).

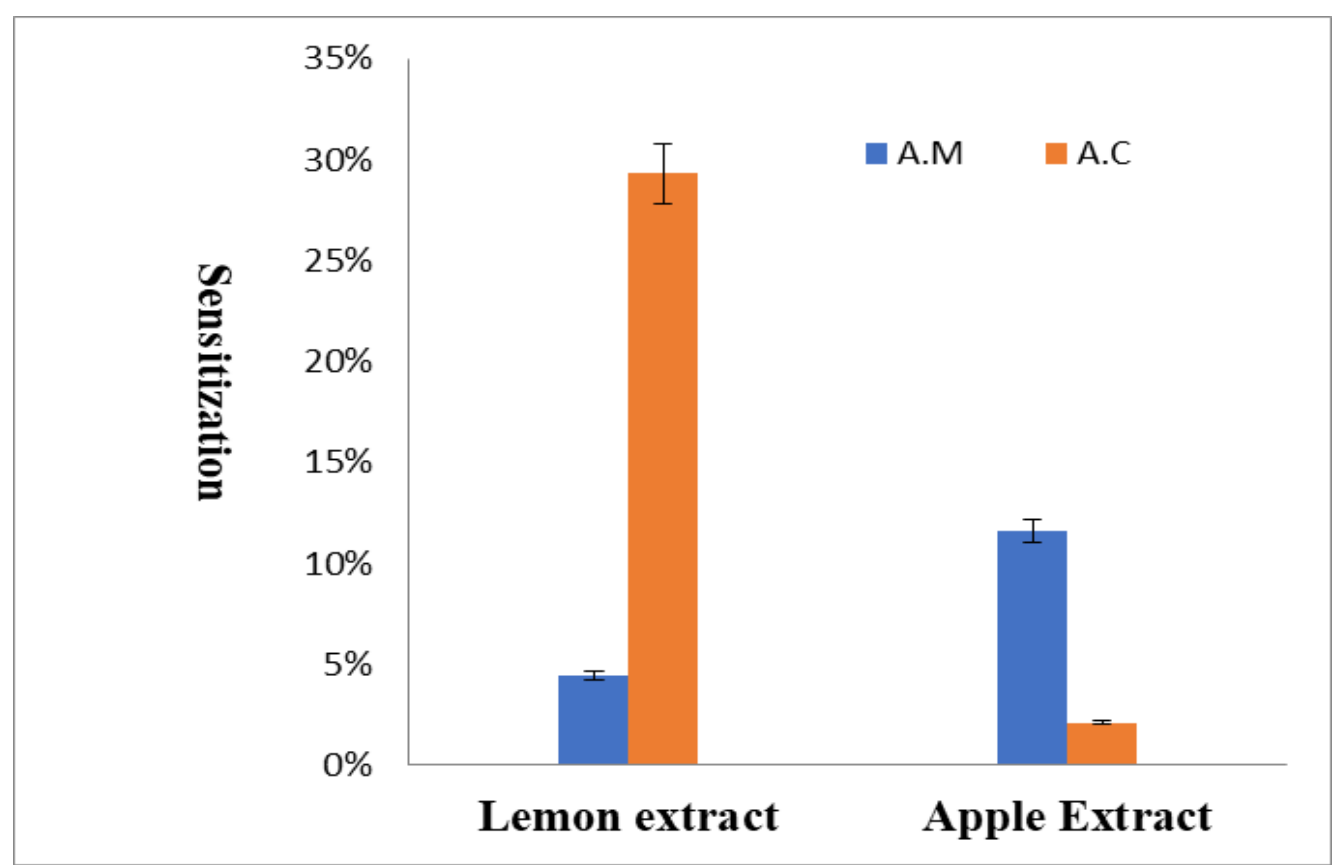

Figure 5. Percentage of sensitization (mean \pm SE) of Apis mellifera and A. cerana for lemon extract and apple extract

\section{Discussions}

Highly responsive bees respond to sucrose solution at concentrations as low as $0.1 \%$ or even to water, whereas unresponsive bees only respond to $30 \%$ of sucrose or higher sucrose concentrations (Scheiner et al., 2004). This study reported that sucrose responsiveness between two species A. mellifera and A. cerana. We demonstrated proboscis extension response (PER) percentage of foragers. These two honeybee species showed different response patterns at different sucrose concentrations when sucrose concentration was low then its proboscis extension response is also low. However, the results in this study indicated that A. mellifera foragers had significant higher proboscis extension percentage than A. cerana foragers at $30 \%$ sucrose. Our finding fits well and strongly agreed with previous studies (Scheiner et al., 2004; Yang et al., 2013). A. mellifera was more responsive than A. cerana. According to previous research work, A. mellifera foragers were more responsive to sucrose. Our conclusion showed that Apis mellifera has higher sucrose responsiveness than Apis cerana. The results of Yang et al. (2013) helped to confirm our conclusion.

Non-associative forms of learning change the behavior of an animal because of the exposure to a stimulus. If the response decreases as a result of repeated stimulation, the animal may have habituated rather than undergone motor fatigue or sensory adaptation (Carew, 1987; Menzel, 1999; Kandel et al., 2000). Habituation signifies the gradually diminish in responsiveness during a continuous series of frequent stimulations. In our 
finding Apis cerana took less time as compared to Apis mellifera. The proboscis extension reflex is an appetitive component of the bee's feeding behavior that is elicited by touching one antenna with a droplet of sugar water. Repetitive stimulation leads to a decrement and finally to the disappearance of the response. This experiment was designed to analyze the role of individual sucrose responsiveness in non-associative habituation and to study the effect of sucrose concentration used as habituating stimuli on non-associative habituation. A wide range of habituation patterns in Drosophila have been investigated, as well as the proboscis extension response, visual escape jump landing response (Braun and Bicker, 1992). Honeybee foragers must fly many kilometers - even more than 6-10 kilometers away - try to collect nectar and pollen. Therefore, they must learn and remember not only the shape and color of the flowers, as well as how to reach them. This experiment was designed to analyze the role of individual sucrose responsiveness in non-associative habituation and to study the effect of sucrose concentration used as habituating stimuli on non-associative habituation (Abramson, 1997;) Giurfa, 2007; Giurfa and Sandoz, 2012; Matsumoto et al., 2012). Memory was developed in a trial and time dependent way that indicates processes of memory formation that can be transmitted to particular areas of the honeybee brain and cellular and molecular processes. Apis mellifera showed significantly stronger learning and memory behavior than A. cerena after $2 \mathrm{~h}$ and $24 \mathrm{~h}$. The finding of this study demonstrated that the percentage of learning and memory behavior of Apis melliferra was significantly higher than Apis cerana after $2 \mathrm{~h}$ and $24 \mathrm{~h}$ as a resulted by Chen (2001), Qin et al. (2012). This could be due to Apis mellifera strain introduced in China has been subjected to intensive artificial selection to be better manageable, while Apis cerana bees were managed well in a half wild condition. These two species of honeybees may have distinct responses to harnessing.

The findings of sensitization study clearly determine that the sensitive stimuli of $A$. cerena against lemon extract were more than A. mellifera, but A. mellifera were more sensitive against apple extract than A. cerena. In addition, the results of this study showed significant differences between Apis Cerana and Apis mellifera in response to lemon and apple extract as revealed by Chen (2001), Apis cerana has an excellent sense of smell than Apis mellifera. Introduced over 100 years ago, in majority regions of China, Apis mellifera is completely developed and adapted to nectar sources and climate. Despite that, to be sure those Apis mellifera bees are not adapted pretty well such as Apis cerana, whose homeland and region is here Qin et al. (2012).Individual sucrose responsiveness and the sucrose concentration used as reward strongly affect associative PER learning. In previous studies comparative behavioral data of color and grating learning and memory for Apis cerana and Apis melliferra in China. This study provides the first evidence of the learning and memory difference between Apis cerana and Apis melliferra under controlled conditions, and it is important for the further study of the mechanisms of learning and memory in honeybees (Giurfa et al., 2001). Yang (2009) described that the niche between A.cerana and A.mellifera is overlap among Apis cerana and Apis mellifera; both of these species have their own characteristic to diminish competition in food. Apis cerana is able to collect sporadic nectar flowers, while Apis mellifera takes advantage of large flower fields. Apis cerana meets the significantly lower selectivity pressure to learn how odors and rewards are associated. This may be possible reasons why Apis cerana did poorer performance than Apis mellifera. After the achievement, there was no distinction in the memory retaining of different odors between these both sibling species. Both species distinguished between experienced scent and un-experienced scent. These findings are consistent with earlier odor learning and odor discrimination studies in bees (Bitterman et al., 1983).We still 
cannot exclude the possibility that rather unspecific parameters could have also influenced our experiments. For example, the two species may have had distinct abilities to adapt to the confined test conditions or may have required different amounts of food in order to achieve satiation meaning that the reward value of the sucrose solution could be different for each species. Apis cerana had lower PER scores than A. mellifera in the first three trials of the acquisition phase, suggesting that it was a slow learner. Which may attribute to the reasons that the strain of A. mellifera introduced in China had been subjected to intense artificial selection to be more docile. While the Apis cerana we utilized were managed in a half-wild situation. Thus, these two bee species could have different reactions to harnessing.

We suggested that Apis Cerana could be investigated by applying classic olfactory PER protocol. Moreover, further work is necessary to reveal the physiology of the olfactory learning method based on this cognitive research.

\section{Conclusion and future}

The most significant and our overall finding show that Apis mellifera foragers are able to store reward information and have better learning and memory versus Apis cerana cerana. But these experiments were first and basic step to understanding the learning, memory and behavior of both species. Various experiment and studies need to explore on different aspects of learning and memory for example different age bees, use of different odor, different kind of behavior, level of brain biogenic amines, and protein synthesis and gene expression in different age bees.

\section{REFERENCES}

[1] Abramson, C. I. (1997): Where have I heard it all before - Comparative psychology of invertebrates: The field and laboratory study of insect behavior. Taylor \& Francis, 1082:55.

[2] Afik, O., Dag, A., Shafir, S. (2006): The effect of avocado (Persea americana) nectar composition on its attractiveness to honey bees (Apis mellifera) - Apidologie. doi: 10.1051/apido:2005064.

[3] Ahmad, S. B., Dar, S. A., Pandith, B. A. (2017): Comparative foraging behaviour of honey bees, Apis cerana f. and Apis mellifera 1. (Hym: Apidae) on apple bloom - Journal of Entomology and Zoology Studies 5(1): 474-482.

[4] Bitterman, M. E. et al. (1983): Classical conditioning of proboscis extension in honey bees (Apis mellifera). - Journal of comparative psychology, Washington, D.C. : 1983. doi: 10.1037/0735-7036.97.2.107.

[5] Braun, G., Bicker, G. (1992): Habituation of an appetitive reflex in the honey bee Journal of Neurophysiology. doi: 10.1152/jn.1992.67.3.588.

[6] Carew, T. (1987): Cellular and molecular advances in the study of learning in Aplysia Neural and molecular bases of learning. - John Wiley and Sons.

[7] Chen, S. L. (2001): The apicultural science in China - China AgriculturePress, Beijing: $1-16$.

[8] Davis, R. L. (2005): Olfactory memory formation in Drosophila: From Molecular to Systems Neuroscience - Annual Review of Neuroscience. doi: 10.1146/annurev.neuro.28.061604.135651.

[9] Duffy, J. E. et al. (2007): The functional role of biodiversity in ecosystems: Incorporating trophic complexity - Ecology Letters. doi: 10.1111/j.1461-0248.2007.01037.x.

[10] Ebeling, A., Klein, A. M., Tscharntke, T. (2011): Plant-flower visitor interaction webs: Temporal stability and pollinator specialization increases along an experimental plant diversity gradient - Basic and Applied Ecology. doi: 10.1016/j.baae.2011.04.005. 
[11] Engel, M. M. S. (1999): The taxonomy of recent and fossil honey bees (Hymenoptera Apidae Apis) - Journal of Hymenoptera Research. doi: https://doi.org/10.1007/978-14614-4960-7_18.

[12] Erber, J., Masuhr, T., Menzel, R. (1980): Localization of short-term memory in the brain of the bee, Apis mellifera - Physiological entomology. doi: 10.1111/j.13653032.1980.tb00244.x.

[13] Friedrich, A. (2004): Learning at Different Satiation Levels Reveals Parallel Functions for the cAMP-Protein Kinase A Cascade in Formation of Long-Term Memory - Journal of Neuroscience. doi: 10.1523/JNEUROSCI.0669-04.2004.

[14] Frings, H., Frings, M. (1949): The Loci of Contact Chemoreceptors in Insects. A Review with New Evidence - American Midland Naturalist 41(3): 602-658.

[15] Frost, E. H., Shutler, D., Hillier, N. K. (2011): Effects of cold immobilization and recovery period on honey bee learning, memory, and responsiveness to sucrose - Journal of Insect Physiology. doi: 10.1016/j.jinsphys.2011.07.001.

[16] Gerber, B., Ullrich, J. (1999): No evidence for olfactory blocking in honey bee classical conditioning - The Journal of experimental biology. doi: PMID: 10359686.

[17] Giurfa, M. et al. (2001): The concepts of "sameness" and "difference" in an insect Nature. doi: 10.1038/35073582.

[18] Giurfa, M. (2007): Behavioral and neural analysis of associative learning in the honey bee: A taste from the magic well - Journal of Comparative Physiology A: Neuroethology, Sensory, Neural, and Behavioral Physiology. doi: 10.1007/s00359-007-0235-9.

[19] Giurfa, M., Sandoz, J. C. (2012): Invertebrate learning and memory: Fifty years of olfactory conditioning of the proboscis extension response in honey bees - Learning and Memory. doi: 10.1101/lm.024711.111.

[20] Haddad, N. M. et al. (2011): Plant diversity and the stability of foodwebs - Ecology Letters. doi: 10.1111/j.1461-0248.2010.01548.x.

[21] Hammer, M., Braun, G., Mauelshagen, J. (1994): Food-induced arousal and nonassociative learning in honey bees: Dependence of sensitization on the application site and duration of food stimulation - Behavioral and Neural Biology. doi: 10.1016/S01631047(05)80019-6.

[22] Hongliang, L. I. (2007): Construction and Analysis of cDNA Library of worker heard from Apis cerana cerana - Apiculture of China.

[23] Hooper, D. U. et al. (2005): Effects of biodiversity on ecosystem functioning: A consensus of current knowledge - Ecological Monographs. doi: 10.1890/04-0922.

[24] Iqbal, J., Mueller, U. (2007): Virus infection causes specific learning deficits in honey bee foragers. - Proceedings. Biological sciences / The Royal Society. doi: 10.1098/rspb.2007.0022.

[25] Kandel, E. R. et al. (2000): Principles of neural science. - McGraw-hill New York.

[26] Kesner, R. P., Olton, D. S. (2014): Neurobiology of comparative cognition. - Psychology Press.

[27] Leonard, A. S., Dornhaus, A., Papaj, D. R. (2011): Flowers help bees cope with uncertainty: signal detection and the function of floral complexity - The Journal of Experimental Biology 214(1): 113-121. doi: 10.1242/jeb.047407.

[28] Lin, Z. et al. (2016): Go east for better honey bee health: Apis cerana is faster at hygienic behavior than A. mellifera - PLoS ONE. doi: 10.1371/journal.pone.0162647.

[29] Matsumoto, Y. et al. (2012): Revisiting olfactory classical conditioning of the proboscis extension response in honey bees: A step toward standardized procedures - Journal of Neuroscience Methods. doi: 10.1016/j.jneumeth.2012.08.018.

[30] Menzel, R. (1999): Memory dynamics in the honey bee - Journal of Comparative Physiology A: Sensory, Neural, and Behavioral Physiology. doi: 10.1007/s003590050392.

[31] Menzel, R. (2012): The honey bee as a model for understanding the basis of cognition Nature Reviews Neuroscience. doi: 10.1038/nrn3357.

[32] Menzel, R., Giurfa, M. (2001): Cognitive architecture of a mini-brain: The honey bee Trends in Cognitive Sciences. doi: 10.1016/S1364-6613(00)01601-6.

[33] Menzel, R., Greggers, U., Hammer, M. (1993): Functional Organization of Appetitive 
Learning and Memory in a Generalist Pollinator, the Honey Bee - Insect Learning. doi: 10.1007/978-1-4615-2814-2_4.

[34] Menzel, R., Leboulle, G., Eisenhardt, D. (2006): Small brains, bright minds - Cell. doi: 10.1016/j.cell.2006.01.011.

[35] Menzel, R., Müller, U. (1996): Learning and memory in honey bees: from behavior to neural substrates - Annual review of neuroscience, Annual Reviews 19(1): 379-404.

[36] Mizunami, M., Yokohari, F., Takahata, M. (2004): Further exploration into the adaptive design of the arthropod "microbrain": I. Sensory and memory-processing systems Zoological Science. doi: 10.2108/zsj.21.1141.

[37] Mota, T. et al. (2011): Visual conditioning of the sting extension reflex in harnessed honey bees - Journal of Experimental Biology. doi: 10.1242/jeb.062026.

[38] Müller, U., Hildebrandt, H. (2002): Nitric oxide/cGMP-mediated protein kinase A activation in the antennal lobes plays an important role in appetitive reflex habituation in the honey bee - The Journal of Neuroscience 22(19): 8739-47. doi: 22/19/8739 [pii].

[39] Oldroyd, B. P., Wongsiri, S. (2009): Asian honey bees: biology, conservation, and human interactions. - Harvard University Press.

[40] Pankiw, T., Page, R. E. (2003): Effect of pheromones, hormones, and handling on sucrose response thresholds of honey bees (Apis mellifera L.) - Journal of Comparative Physiology A: Neuroethology, Sensory, Neural, and Behavioral Physiology. doi: 10.1007/s00359-003-0442-y.

[41] Pankiw, T., Waddington, K. D., Page, R. E. (2001): Modulation of sucrose response thresholds in honey bees (Apis mellifera L.): Influence of genotype, feeding, and foraging experience - Journal of Comparative Physiology A: Sensory, Neural, and Behavioral Physiology. doi: 10.1007/s003590100201.

[42] Pérez Claudio, E. et al. (2018): Appetitive reversal learning differences of two honey bee subspecies with different foraging behaviors - PeerJ. doi: 10.7717/peerj.5918.

[43] Pirk, C. W. W. et al. (2013): Statistical guidelines for Apis mellifera research - Journal of Apicultural Research 52(4): 1-24. doi: 10.3896/IBRA.1.52.4.13.

[44] Qin, Q.-H. H. et al. (2012): Comparison of learning and memory of Apis cerana and Apis mellifera - Journal of Comparative Physiology A: Neuroethology, Sensory, Neural, and Behavioral Physiology. doi: 10.1007/s00359-012-0747-9.

[45] Sandoz, J. C. (2011): Behavioral and Neurophysiological Study of Olfactory Perception and Learning in Honey bees - Frontiers in Systems Neuroscience. doi: 10.3389/fnsys.2011.00098.

[46] Sandoz, J. C., Hammer, M., Menzel, R. (2002): Side-specificity of olfactory learning in the honey bee: US input side - Learning and Memory. doi: 10.1101/lm.50502.

[47] Scheiner, R., Erber, J., Page, R. E. (1999): Tactile learning and the individual evaluation of the reward in honey bees (Apis mellifera L.) - Journal of Comparative Physiology - A Sensory, Neural, and Behavioral Physiology. doi: 10.1007/s003590050360.

[48] Scheiner, R., Page, R. E., Erber, J. (2001): The effects of genotype, foraging role, and sucrose responsiveness on the tactile learning performance of honey bees (Apis mellifera L.) - Neurobiology of Learning and Memory. doi: 10.1006/nlme.2000.3996.

[49] Scheiner, R., Page, R. E., Erber, J. (2004): Sucrose responsiveness and behavioral plasticity in honey bees (Apis mellifera) - Apidologie. doi: 10.1051/apido.

[50] Seeley, T. (1995): The Wisdom of the Hive, Book. doi: 10.1016/j.desal.2010.03.003.

[51] Spear, N. E., Miller, J. S., Jagielo, J. A. (1990): Animal memory and learning. - Annual review of psychology. doi: 10.1146/annurev.psych.41.1.169.

[52] Takeda, K. (1961): Classical conditioned response in the honey bee - Journal of Insect Physiology. doi: 10.1016/0022-1910(61)90060-9.

[53] Tilman, D. et al. (2001): Diversity and productivity in a long-term grassland experiment Science. doi: $10.1126 /$ science. 1060391 .

[54] Vareschi, E. (1971): Duftunterscheidung bei der Honigbiene - Einzelzell-Ableitungen und Verhaltensreaktionen - Zeitschrift fuer Vergleichende Physiologie. doi: 10.1007/BF00335260.

[55] Wang, F.-H. et al. (2007): Conservation and utilization of the Chinese honey bee Apis 
cerana in Bejing $[\mathrm{J}]$ - Chinese Bulletin of Entomology 6: 37 .

[56] Winston, M. L. (1991): The biology of the honey bee. - Harvard university press.

[57] Yang, W. et al. (2013): Comparative Sucrose Responsiveness in Apis mellifera and A. cerana Foragers - PLoS ONE. doi: 10.1371/journal.pone.0079026. 